Rev. Elet. em Gestão, Educação e Tecnologia Ambiental (e-ISSN: 2236-1170)

\title{
LEVANTAMENTO PARCIAL DA AVIFAUNA APREENDIDA PELO ESCRITÓRIO REGIONAL DO IBAMA DE SANTA MARIA-RS
}

PARTIAL LIST AVIFAUNA SEIZED BY REGIONAL OFFICE OF SANTA MARIA IBAMA-RS

\author{
Roselene Marostega Felker, Andréa Cristina Dörr, Ana Paula Rovedder, Eliara Marin Piazza, \\ Grasiele Dick
}

http://dx.doi.org/10.5902/223611708734

\section{RESUMO}

A avifauna brasileira está entre as mais diversas do mundo e também entre as mais traficadas. Diante desse cenário, o presente trabalho visa à realização de levantamento da avifauna apreendida pelo Escritório Regional do IBAMA de Santa Maria, durante os períodos de 2006, 2007 e 2008, através de autos de infração lavrados pelos analistas ambientais. Observou-se no levantamento, a apreensão de 1.250 indivíduos, em diferentes regiões do estado. Dentre estes, Paroaria coronata, foi a espécie com mais indivíduos apreendidos, seguido do Sicalis flaveola e Cyanocompsa brissonii. A família com maior número de representantes apreendidos foi a Emberizidae, seguida da Psittacidae, sendo Santa Maria a cidade com maior número de autos de infrações contra a avifauna, registrado nesse levantamento. Levando em conta que a maioria das aves apreendidas tem como destino final a domesticação, se faz necessário maior conscientização da população, para que não haja a sustentação desse tipo de tráfico que envolve a fauna brasileira.

Palavras-chave: autos de infração, fauna brasileira, tráfico de animais

\begin{abstract}
ABSCTRAT
Brazilian birdlife is among the most diverse in the world and also among the most trafficked. Against this backdrop, this paper aims to carry out survey of birds seized by the Regional Office of IBAMA Santa Maria, during the periods 2006, 2007 and 2008, through deficiency notices issued by environmental analysts. It was observed in the survey of 1250 individuals apprehension in different regions of the state. Among these, Paroaria coronata, was the species most individuals seized, followed by Sicalis flaveola and Cyanocompsa brissonii. The family with the largest number of representatives was seized Emberizidae, then the Psittacidae, and Santa Maria, the city with the largest number of notices of infractions against the avifauna recorded in this survey. Considering that most birds have learned how domestication final destination, it is necessary to raise awareness of the population, so there is no support of such trafficking, involving the Brazilian fauna.
\end{abstract}

Keywords: Brazilian fauna, animal trafficking, tax assessments.

INTRODUÇÃO 


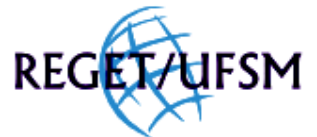

FELKER et all, v(11), no 11, p. 2506-2510 , JUN, 2013.

Rev. Elet. em Gestão, Educação e Tecnologia Ambiental (e-ISSN: 2236-1170)

O Brasil é um dos países em destaque quanto à biodiversidade animal, dentre estes, a avifauna brasileira, que contribui com cerca de 1.680 espécies incluindo aves residentes e as visitantes (SICK, 1997).

Hoje inúmeras aves são retiradas de seus habitats para serem comercializadas transformando o tráfico de animais silvestres em um dos maiores comércios ilícitos do mundo, perdendo apenas para o tráfico de armas e narcotráfico (LE DUC, 1996). Dentre esta grande porcentagem de tráfico de animais selvagens a avifauna se encontra entre as mais traficadas.

De modo geral, os países em desenvolvimento são os principais fornecedores de vida silvestre, com parte de suas populações sobrevivendo dessa atividade (HEMLEY \& FULLER, 1994) e os principais países consumidores são: os EUA (maior consumidor de vida silvestre do mundo), Alemanha, Holanda, Bélgica, França, Inglaterra, Suíça, Grécia, Bulgária, Arábia Saudita e Japão (HARDIE, 1987; ROCHA, 1995; LE DUC, 1996). No Brasil, a maioria dos animais silvestres comercializados ilegalmente é proveniente das regiões Norte, Nordeste e Centro-Oeste, sendo escoada para as regiões Sul e Sudeste, pelas rodovias federais (RENCTAS, 1999).

O estado do Rio Grande do Sul, em especial possui o agravante de estar localizado em área estratégica para o tráfico animal servindo de corredor de escoamento, para a passagem da fauna traficada avançar até outros países. Destes animais traficados ilegalmente para fora do país, muitas espécies recebem documentação falsa como se fossem nativos desses países.

Para proteção da fauna brasileira foi legitimada a Lei no. 5.197/67, a primeira legislação própria de proteção à fauna silvestre no Brasil, tratando a infração como contravenção penal. Desde então a legislação foi sendo modificada, atualmente está em vigência a Lei no. 9.605, de 12 de fevereiro de 1998 - Leis de Crimes Ambientais, que prevê a substituição das penas privativas de liberdade, por penas restritivas de direito, tais como prestação de serviço à comunidade, suspensão temporária de direito, suspensão parcial ou total de atividades, prestação pecuniária e recolhimento domiciliar.

O presente trabalho é um levantamento preliminar sobre a avifauna traficada na região de abrangência do escritório regional do Instituto Brasileiro do Meio Ambiente e dos Recursos Naturais Renováveis (IBAMA) de Santa Maria, RS. São apresentados os dados referentes ao inventariamento quali-quantitativo das espécies apreendidas pela fiscalização da fauna.

\section{METODOLOGIA}

Os dados levantados para esta pesquisa foram obtidos através dos Laudos de infração lavrados no IBAMA, onde constam as informações relativas às apreensões feitas, espécime recolhida, local da infração, data da autuação e destino das espécies apreendidas. $O$ escritório regional do IBAMA de Santa Maria cobre as regiões noroeste e central do estado.

Para a identificação das aves recolhidas, o IBAMA realiza possui a contribuição de seus analistas ambientais e, ainda, recebe a ajuda da Universidade Federal de Santa Maria (UFSM).

Com relação às aves apreendidas, foi registrada a data de autuação, quantidade de animais por espécie e a região onde ocorreu a infração. 


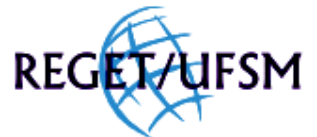

FELKER et all, v(11), no 11, p. 2506-2510 , JUN, 2013.

Rev. Elet. em Gestão, Educação e Tecnologia Ambiental (e-ISSN: 2236-1170)

A nomenclatura utilizada para referir as espécies segue Bencke (2001). Já a bibliografia utilizada para descrever a categoria de ameaça das espécies foi o Decreto Estadual 41.672/02 e a Lista Nacional das Espécies da Fauna Brasileira Ameaçada de Extinção.

Os dados coletados, organizados e sumarizados através da estatística descritiva, são baseados em porcentagens, uma vez que não foi possível a obtenção de $100 \%$ dos levantamentos de apreensões feitas pelo IBAMA, pelo fato de haver dificuldades na visualização dos referidos documentos. A documentação não analisada se refere a aproximadamente 27 laudos de infração.

\section{RESULTADOS E DISCUSSÃO}

Foram contabilizados informações de 2006, 2007 e 2008 para realizar o levantamento da avifauna, o que totalizou aproximadamente 1.250 espécimes de aves apreendidas neste período.

As sete espécies mais apreendidas foram, em ordem decrescente, o cardeal (Paroaria coronata) com aproximadamente 390 indivíduos, o equivalente a $41 \%$ do total de aves apreendidas, o canário da terra (Sicalis flaveola) com 165 indivíduos e 18\% do total, o azulão (Cyanocompsa brissonii), representado por 142 espécimes e 15\%, trinca-ferro (Saltator similis) com 76 indivíduos e 8\%, pintassilgo (Carduelis magellanica) com 65 indivíduos e 7\% geral, o Coleirinho (Sporophila caerulescens) com 55 indivíduos e $6 \%$ e a apreensão de 45 caturritas (Myiopsitta monachus) que colaborou com $5 \%$ do total de registros.

Agrupadas por famílias, observa-se que a família com mais representantes apreendidos foi a Emberizidae, com cerca de 983 indivíduos, seguida pela família Psittacidae com 109 indivíduos.

Ao avaliar apreensões em quantidade/ano, o IBAMA contabilizou cerca de 347 indivíduos apreendidos em 2006, 501 indivíduos no ano de 2007 e 402 animais em 2008.

Da avifauna apreendida o pássaro Cardeal (Paroaria coronata), foi o mais apreendido em todos os anos, com 143 apreensões em 2006, 106 no ano de 2007 e 134 no ano de 2008. Vale salientar, que a ave Paroaria coronata, hoje não está em perigo de extinção, mas com essa crescente demanda do tráfico, demanda cuidados de proteção a esta ave.

Conforme o Decreto Estadual 41.672/02 e a Lista Nacional das Espécies da Fauna Brasileira Ameaçada de Extinção de 2003, as aves apreendidas no decorrer da pesquisa e classificadas com algum grau de perigo são: Gubernatrix cristata de nome popular Cardealamarelo que consta na categoria de ameaça criticamente em perigo no RS no Decreto estadual e Lista nacional; o Papagaio Charão (Amazona pretrei), na categoria vulnerável no RS e SC constando no Decreto e na lista nacional; Tiê-tinga (Cissopis leveriana) na categoria vulnerável conforme Decreto Estadual; Gaturamo (Euphonia violacea), na categoria vulnerável conforme Decreto Estadual.

Os dados dessa pesquisa mostram de maneira geral, a grande pressão antrópica sofrida, especialmente pela família Emberizidae, com o maior número de aves apreendidas, e como as aves canoras são requisitadas no mercado ilegal do tráfico de animais.

Do grande contingente de aves apreendidas, aquelas que apresentarem condições adequadas, são soltas no ambiente similar a aquele em que foi retirado, o que explica muitas vezes o registro de novas ocorrências de algumas espécies no estado. Esse é o caso de Paroaria 


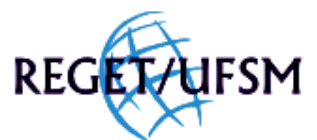

FELKER et all, v(11), no 11, p. 2506-2510 , JUN, 2013.

Rev. Elet. em Gestão, Educação e Tecnologia Ambiental (e-ISSN: 2236-1170)

dominicana, espécie natural da Região Nordeste do país e que é facilmente encontrada na cidade de Porto Alegre, RS (SICK, 1997).

A imensa biomassa de $P$. coronata, 390 indivíduos apreendidos, representa apenas uma parte da pressão antrópica a que ela está sendo submetida, uma vez que a maior parte não chega a ser apreendida ou mesmo morre nesse processo (POTEN, 1991; LE DUC, 1996). Apesar do cardeal não estar nas listas oficiais de animais em perigo, esta ave vem sendo o foco principal de vários diagnósticos realizados sobre o tráfico de aves. Segundo Ferreira (2001), em seu relatório Diagnóstico preliminar sobre a avifauna traficada no Rio Grande do Sul, nos anos de 98, 99 e 2000, o cardeal já se mostrava como a ave mais traficada com cerca de 1.088 indivíduos apreendidos durante esse período no estado do estado do RS.

Outro resultado constatado através do levantamento foi a verificação do número de infrações autuadas pela fiscalização por cidade de abrangência do escritório regional do IBAMA de Santa Maria. Verificou-se que no ano de 2006, o maior número de apreensões foi realizado nas cidades de Cacequi e Santa Maria, com 26 e $28 \%$ de apreensões, respectivamente. No ano de 2007, as cidades com maiores apreensões foram Santa Rosa e Santa Maria, ambas com um total de $23 \%$ em apreensões. No ano de 2008 Santa Maria apresentou o maior número de infrações. A verificação do maior número de autuações para os três anos pesquisados apontou Santa Maria como a cidade com maior número de infrações. Esse fato pode ser decorrente da presença do escritório de autuação do IBAMA estar sediado na cidade de Santa Maria e por isso há um maior controle sobre os casos de avifauna traficadas nesse local.

O brasileiro sempre manteve especial predileção por aves de gaiola, sendo os pássaros canoros as espécies mais encontradas em cativeiro no Brasil (SANTOS, 1985; SOUZA, 1987). Os psitacídeos, devido à habilidade de imitar a voz humana, combinada com a inteligência, beleza e docilidade, são as aves mais populares e procuradas como animal de estimação no mundo, ficando atrás apenas dos cachorros e gatos. Estas características contribuem para que sejam as aves mais comercializadas ilegalmente (ABRAMSON et al., 1995).

As aves apreendidas nas regiões de abrangência do escritório do IBAMA, que não puderem ser soltas em seus habitats são transferidas em sua grande maioria para o Criadouro Conservacionista São Braz, onde são reabilitadas a voltarem à natureza.

\section{CONCLUSÕES}

O tráfico de animais, em especial a avifauna, apresenta contribuição da população que procura animais selvagens para a domesticação ou exposição e não esta ciente do problema ambiental causado.

Para controlar e combater o tráfico de animais selvagens é relevante mais estudos e dados sistematizados sobre esta atividade. $O$ trabalho aqui desenvolvido representa uma pequena contribuição para a conscientização da população frente à problemática da ilegalidade do tráfico da fauna brasileira.

\section{AGRADECIMENTOS}

http://cascavel.ufsm.br/revistas/ojs-2.2.2/index.php/reget 
Rev. Elet. em Gestão, Educação e Tecnologia Ambiental (e-ISSN: 2236-1170)

Ao escritório regional do Instituto Brasileiro de Meio Ambiente e Recursos renováveis (IBAMA), do município de Santa Maria, RS, pela disponibilização dos autos de infração para a realização desta pesquisa.

\section{REFERÊNCIAS BIBLIOGRÁFICAS}

ABRAMSON, J; SPEER , B. L.; THOMPEN, J. B. The large macaws: their care, breeding and conservation. In: The large macaws, Fort Bragg, California, Raintree Publications, 1995. 79-93 p.

BENCKE, G. A. Lista de referência das aves do Rio Grande do Sul. Porto Alegre: Fundação Zoobotânica do Rio Grande do Sul, 2001. 104 p.

BRASIL. Ministério da agricultura. Lei $n^{\circ} 5.197$, de 3 de janeiro de 1967. Dispõe sobre a proteção à fauna e dá outras providências. Brasília, 1967.

BRASIL. Ministério do Meio Ambiente. Lei no 9.605, de 12 de fevereiro de 1998. Lei de Crimes Ambientais. Dispõe sobre as sanções penais e administrativas derivadas de condutas e atividades lesivas ao meio ambiente, e dá outras providências. Brasília, 1998.

FERREIRA, C. M. Diagnóstico da avifauna capturada ilegalmente no Estado do Rio Grande do Sul, Brasil. $70 \mathrm{f}$. Dissertação (Mestrado em Biociências) - Faculdade de Biociências, PUCRS, Porto Alegre, 2001. 35 p.

HARDIE, L. C. Wildlife trade education kit. WWF/TRAFFIC (USA), Washington, 1987, 132 p.

HEMLEY, G.; FULLER K. S. International Wildlife Trade: a CITES Sourcebook. WWF/Island Press, Washington, 1994.166 p.

LE DUC, J. P. Trafficking in animals and plants: a lucrative form of crime. International Criminal Police - ICPO, n. 458/459, p. 19-31, 1996.

MINISTÉRIO DO MEIO AMBIENTE. Lista Nacional das Espécies da Fauna Brasileira Ameaçadas de Extinção (MMA maio de 2003).

POTEN, C. A shameful harvest. National Geographic, v. 180, n. 3, 1991. p.106-132.

RENCTAS. Animais Silvestres: normatização e controle. Rede Nacional Contra o Tráfico de Animais Silvestres, Rio de Janeiro, 1999.

RIO GRANDE DO SUL. Decreto № 41.672, de 11 de junho de 2002. Declara as Espécies da Fauna Silvestre Ameaçadas de Extinção no Estado do Rio Grande do Sul e dá outras providências. Porto Alegre, 2002.

ROCHA, F. M. Tráfico de Animais Silvestres. WWF. Documento para discussão, 1995.

SANTOS, E. Amador de pássaros. Editora Itatiaia, Belo Horizonte, 1985.191 p.

SICK, H. Ornitologia Brasileira, 3o edição. Rio de Janeiro: Nova Fronteira. 1997. 862 - 912 p.

SOUZA, D. Aves do Brasil. Editora Itatiaia, Rio de Janeiro, 1987. 159 p. 